\title{
DESIGN AND CONSTRUCTION OF SMART SOLAR LED LIGHT BULB WITH REMOTE CONTROL
}

\author{
Siralapu Ashok ${ }^{1}$, Basvapuram Srikanth ${ }^{2}$ \\ ${ }^{I}$ Department of Mechanical Engineering, IARE - Institute of Aeronautical Engineering, Hyderabad, India \\ ${ }^{2}$ Department of Mechanical Engineering, IARE - Institute of Aeronautical Engineering, Hyderabad, India
}

\begin{abstract}
The ever increasing demand for electricity requirements of the world puts mankind in search of a new form of energy source that could generate electricity with less or no wastage and cause no environmental damage. The prime concern of this project is to design and develop a system which is cost effective and cause no pollution. Keeping this in mind in this paper we are discussing SMART SOLAR LED LIGHT BULB WITH REMOTE CONTROL. The power consumption of this system is less because its brightness is adjustable with IR remote control, and use of LEDs occupy less space and consumes less power and has a longer lifespan. This light bulb can conserve a large amount of electric power as it completely reliable on solar energy and does not use conventional electricity generated by the power stations. This light bulb is designed to save a large amount of power compared to conventional CFL bulbs which glows with its maximum intensity after they are turned on. This system not only saves electricity but also brings down the total cost involved in making a rechargeable led light bulb. If this technology implemented in street lights eliminates manual work of switching $O N$ and $O F F$.
\end{abstract}

Keywords: remote control, solar panel, light bulb, rechargeable battery, LEDs. ****

\section{INTRODUTION}

The main objective of our project is to provide an alternate lighting system by using solar energy, for which we designed and developed a low cost solar powered remote control lighting system. Our project includes various components namely solar light bulb, integrated circuit, some wiring, infrared receiver module, battery, solar panel.

A lamp is a portable lighting device which converts the electrical energy from a battery or any other source into visible light. It is basically a prime mover which converts one form of energy say (electrical energy) into other form say (light energy). It is estimated that by the year 2020 solar energy would be the world's leading and largest source of energy. Unlike the traditional fossil fuels (i.e., Coal, Petroleum, and natural gas) solar energy is a clean, pollution free, inexpensive, inexhaustible source of energy available all around the world. This rechargeable light bulb serve as an alternative lighting solution in remote areas where there is lack of electricity supply. A solar cell or photovoltaic cell is a device which converts sunlight into direct current, as sunlight falls on the solar cell, it creates a chemical reaction in it and thus produce a stream of electron flow called electricity, and this generated current is dependent on several other parameters such as intensity of Sunlight and weather conditions.

The battery employed in this bulb gets recharged throughout the day as sunlight continues to be converted into electricity. The battery supplies current to the light bulb whenever required, providing the unit with remote control adds extra benefits and improves the flexibility of the system.

\section{COMPONENTS REQUIRED}

1. Infrared receiver module with remote control

2. Light bulb housing and LEDs (21)

3. Light diffuser

4. Rechargeable battery (3.7volts, $2000 \mathrm{mah}$ lithium ion)

5. Solar panel (6volts, 2.5 watts)

6. Charge controller circuit (6v, 3Amps)

\subsection{Block Diagram of Working System}

Figure1 shows the components used in our solar led light bulb:

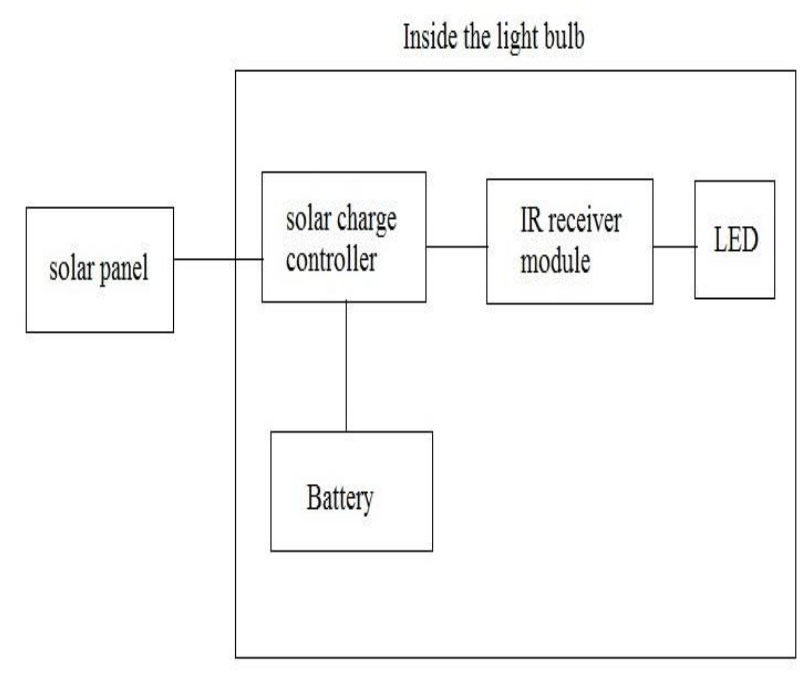

Fig 1 
(a) Lamp unit: It consists of series of LEDs along with an infrared receiver, battery, charge controller module, light diffuser which equally distributes the light to a wide angle.

(b) Infrared receiver unit: It consists of IR receiver which is powered by $3.7 \mathrm{v}$ battery. This module is used to demodulate $38 \mathrm{kHz}$ signals.

(c) Solar panel unit: It consists of a series of solar cells. It is used to continuously recharge the battery, the solar panel that we are using this system is a 6volts 2.5 wattage.

(d) Battery unit: it consists of a single 3.7 volts rechargeable lithium ion battery of capacity 2000mah. Which can be recharged over more than 500 times.

(e) Charge controller unit: it is basically a circuit which protects the battery and keeps the battery from overcharging and thus enhance the battery life. Its main purpose is to supply and regulates direct current output from the solar panel and continuously recharge the battery.

\section{EXPERIMENTAL METHODOLOGY}

The light bulb housing holds the charge controller circuit in its upper portion, lower portion consists of series of LEDs connected along with a diffuser which dissipates the light equally in all the directions. Connect the battery terminals to the solar charge controller and connect the output wires to the infrared receiver module, now the solar panel is connected to the charge controller module which regulates and supply constant output current and thus continuously recharges the battery. Make sure that all the terminals are connected accordingly say positive to positive and negative to negative, otherwise change the polarity if found wrong.

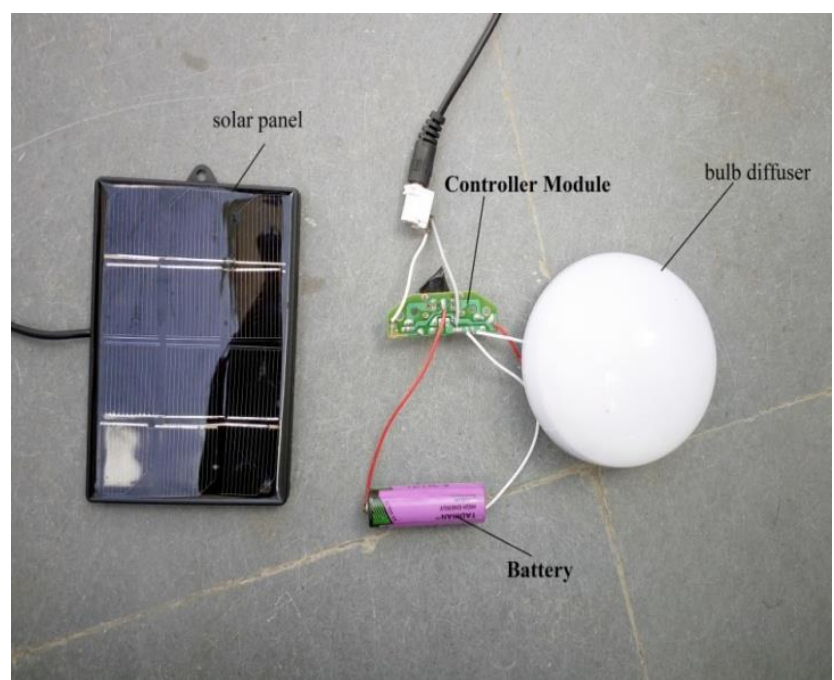

Fig 2

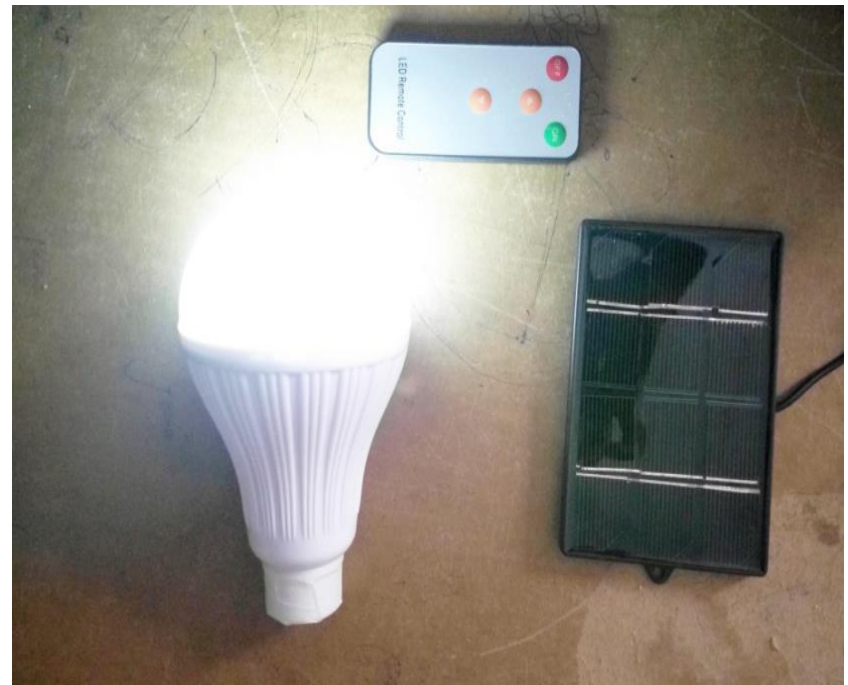

Fig 3

Now the above system works as follows the light from the sun hits the solar panel which converts light energy into electrical energy due to photovoltaic effect and thus flow of electrons occurs, this stream of flowing electrons is named as electricity, this electricity is diverted into solar charge controller which is employed to give a constant output voltage and thus continuously recharge the lithium ion battery, it also safe guard's the battery from overcharging. The output from the battery is then supplied to the infrared receiver module which supplies and regulates the output voltage according to instructions given from the remote control. The output from the receiver is varied and supplied to light up the LEDs present in the bulb.

\section{OBJECTIVES OF THE WORK}

The main objectives of this paper is described in below:

- To design and develop a low cost led light bulb with battery which best serves during long power cuts, emergency lighting.

- To recognize the total cost incurred in making a smart solar led light bulb.

- To design a smart light bulb which saves power by adjusting brightness of light bulb (dimmable)

- To improve the performance of a led light bulb and make the bulb more flexible by introducing remote control.

\section{COST ANALYSIS OF THE SYSTEM}

The total cost involved in this project is as follows:

(All the materials are locally purchased in electronic shop)

1. Solar panel ( 2.5 watt $)=380 \mathrm{Rs}$

2. Light bulb housing with led $=95 \mathrm{Rs}$

3. Battery $(2000 \mathrm{mah})=150 \mathrm{Rs}$

4. Infrared remote control module $=190 \mathrm{Rs}$

5. Miscellaneous cost $=50 \mathrm{Rs}$

TOTAL COST OF THE BULB = 865 Rs

THE COST OF A CONVENTIONAL CFL INVERTER

LIGHTING SYSTEM = 1200 Rs

COST SAVINGS $=335$ Rs 


\section{RESULTS AND DISCUSSION}

This rechargeable low-cost smart led light works efficiently during dark conditions and the introduction of the remote control makes this light bulb dimmable (brightness adjustable) and thus expand the lifespan of the battery by reducing the rate of discharge compared to other conventional rechargeable lamps.

- From the above cost analysis, it is very clear that this project brings down the total cost of a solar rechargeable led light bulb by around $28 \%$ compared to the conventional CFL lighting system.

- The light is powered by a 2000 mah battery which when fully charged can give light for 4-5 hours on full brightness mode.

- The bulb is made out of 21 LEDs which works by consuming 6volts, 0.48amps, the light bulb on its full brightness emits 450 lumens of light.

\section{CONCLUSION}

This project "DESIGN AND CONSTRUCTION OF SMART SOLAR LED LIGHT BULB WITH REMOTE CONTROL" is a low cost, maintenance free, rechargable, eco-friendly and found to be the safest way to save energy. It clearly handles two problems the world has been facing nowadays it saves energy and causes no pollution.

\section{REFERENCES}

[1]. "Survey on Street Lighting System Based On Vehicle Movements" International Journal of Innovative Research in Science, Engineering and Technology ISSN: 2319-8753

[2]. "Survey on Street Lighting System Based On Vehicle Movements" International Journal of Innovative Research in Science, Engineering and Technology ISSN: 2319-875

[3]. "Energy Saving Using LED Automatic Street Light Control System" ,Mitsu Shah1, Charmi Shah2, Hardik Shah3, Riddhi Shah4,J.M. Rathod5 T. D. Pawar6, V. N. Kamat7 .IJREAT International Journal of Research in Engineering \& Advanced Technology, Volume 2, Issue 2, Apr-May, 2014

[4]. Zhong Yi He, Hong Chen "Integrated Solar Controller for Solar Powered Off-grid Lighting System" proceeding by ELSEVIER, Sept. 2011

[5]. M.Abhishek, Syed ajram shah, K.Chetan, K,Arun Kumar, Design and implementation of traffic flow based street light control system with effective utilization of solar energy, International journal of Science Engineering and Advance Technology, IJSEAT, Vol 3, Issue 9, September 2015

[6]. "Intelligent Street Lighting System Using GSM" International Journal of Engineering Science Invention ISSN (Online): 2319 - 6734, ISSN (Print): 2319 6726Volume 2 Issue 3 March. 2013

\section{BIOGRAPHIES}

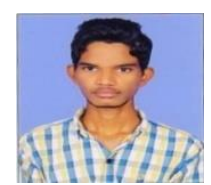

Siralapu Ashok, received B.Tech degree in 2017 in mechanical engineering from institute of aeronautical engineering college, Dundigal, Hyderabad, Telangana, India.

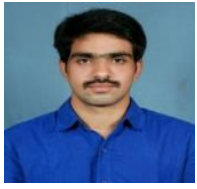

Basvapuram Srikanth, received B.Tech degree in 2017 in Mechanical Engineering from Institute of Aeronautical Engineering College, Dundigal, Hyderabad, Telangana, India. 